\title{
Evaluation of restless legs syndrome symptoms in patients with and without the diagnosis of type 2 diabetes mellitus
}

\author{
Arthur Onofre Beltran Filho*, Guilherme Andreas Jung, Leandro Vicente Zoehler, Josue Cortez, \\ Aline Vieira Scarlatelli Lima
}

From 20th Brazilian Diabetes Society Congress

Porto Alegre, Brazil. 11-18 November 2015

\section{Background}

Restless legs syndrome (RLS) is a neurological sleep disorder. Literature suggests association between RLS and diabetes, but few studies have been done evaluating the association between these conditions [1].

\section{Objective}

Evaluate the prevalence of RLS symptoms in patients with and without the diagnosis of Type 2 Diabetes Mellitus (DM2).

\section{Materials and methods}

Case control study. 112 individuals were studied, 28 with DM2 (cases) and 84 without DM2 (controls), in a medical clinic specialities at Tubarão, Brazil. They answered a questionnaire with socio demographic questions, information about diabetes and to the four minimum criteria, defined by The International Restless Legs Syndrome Study Group (IRLSSG), for RLS diagnosis [2]. Furthermore, they were subjected to the Epworth Sleepiness scale and the IRLSSG rating scale, both translated and validated to Portuguese[3,4].

\section{Results}

Among the cases, $21.4 \%$ presented RLS, compared to $14.3 \%$ in controls $(\mathrm{p}=0.269)$. The group with DM2 showed higher prevalence of Excessive daytime Sleepiness (EDS) ( $21.4 \%$ vs. $13.1 \% ; \mathrm{p}=0.219$ ), and had higher scores in the IRLSSG rating scale $(23,3 \pm 11,3$ vs. $15,7 \pm 6,5 ; \mathrm{p}=0.086)$. Correlating severity of RLS with glycemia, we obtained a Pearson correlation of $0.698(\mathrm{p}=0.003)$.

\section{Conclusions}

DM2 patients have a higher, but non-significant prevalence of RLS symptoms and EDS than the non-diabetics. It has been found a correlation between RLS severity and glycemia.

\section{Published: 11 November 2015}

\section{References}

1. Innes KE, Selfe TK, Agarwal P: Restless legs syndrome and conditions associated with metabolic dysregulation, sympathoadrenal dysfunction, and cardiovascular disease risk: a systematic review. Sleep Med Rev 2012, 16(4):309-39.

2. Allen RP, Picchietti D, Hening WA, Trenkwalder C, Walters AS, Montplaisi J, et al: Restless legs syndrome: diagnostic criteria, special considerations, and epidemiology. A report from the restless legs syndrome diagnosis and epidemiology workshop at the National Institutes of Health. Sleep Med 2003, 4(2):101-19.

3. Bertolazi AN, Fagondes SC, Hoff LS, Pedro VD, Barreto M, Saldanha S, et al: Portuguese-language version of the Epworth sleepiness scale: validation for use in Brazil. J Bras Pneumol 2009, 35(9):877-83.

4. Masuko AH, Carvalho LBC, Machado MAC, Morais JF, Prado LBF, Prado GF: Translation and validation into the Brazilian Portuguese of the restless legs syndrome rating scale of the International Restless Legs Syndrome Study Group. Arq Neuropsiquiatr 2008, 66(4):832-6.

doi:10.1186/1758-5996-7-S1-A89

Cite this article as: Filho et al:: Evaluation of restless legs syndrome symptoms in patients with and without the diagnosis of type 2 diabetes mellitus. Diabetology \& Metabolic Syndrome 2015 7(Suppl 1):A89.

* Correspondence: onofre.arthur@gmail.com

Universidade do Sul de Santa Catarina, Tubarão, Brazil

(c) 2015 Filho et al. This is an Open Access article distributed under the terms of the Creative Commons Attribution License (http:// 